
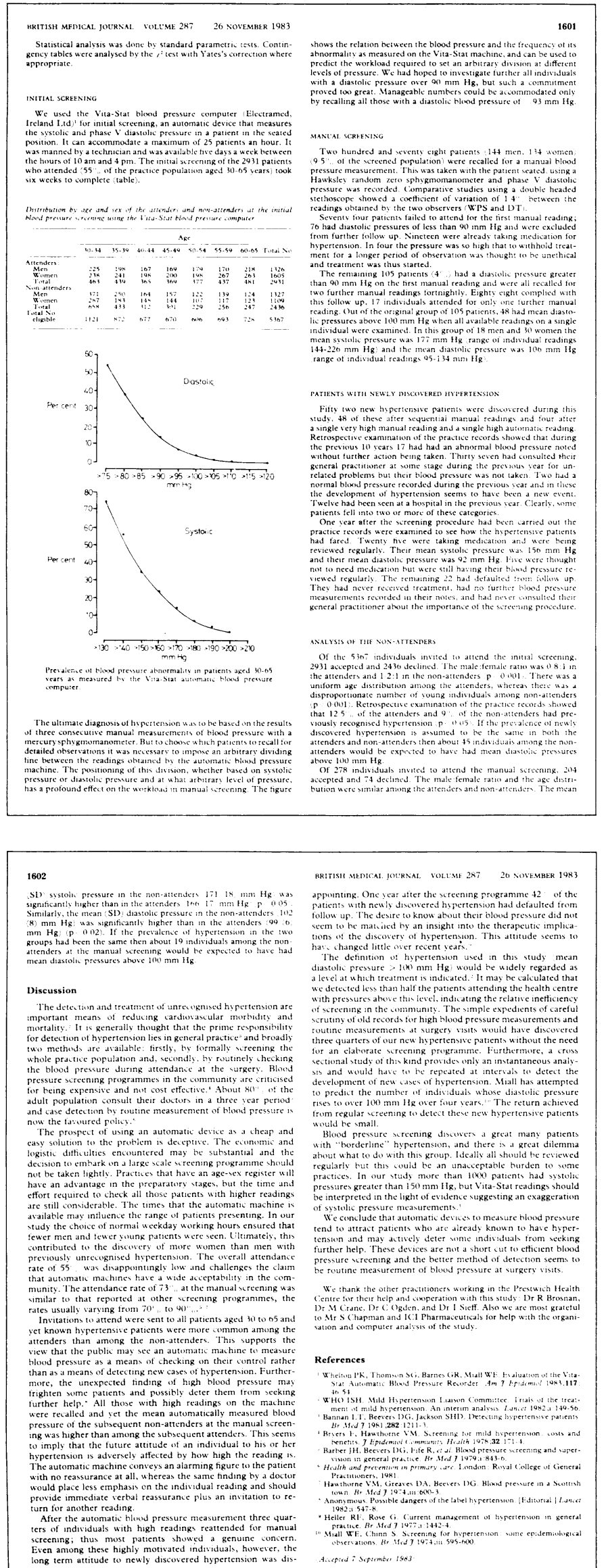

\begin{tabular}{|c|c|c|}
\hline 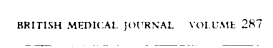 & 26 NONEMAER 1983 & 1603 \\
\hline
\end{tabular}

\section{No man is an island}

ALISTAIR D GRASSIE

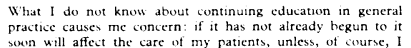

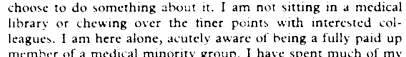

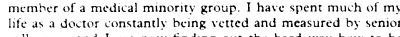

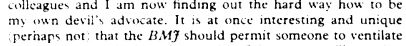

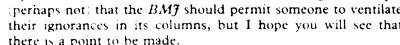

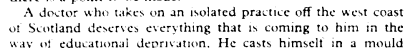

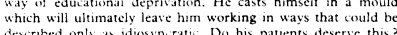

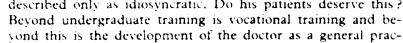

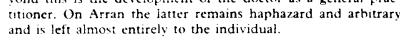

My education

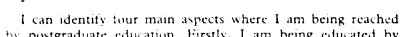

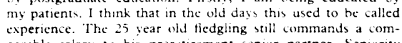

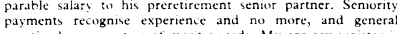

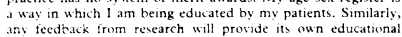

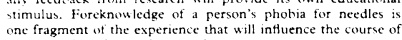

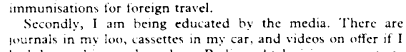

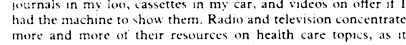

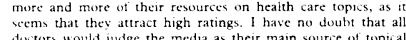

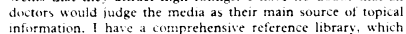

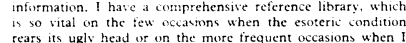

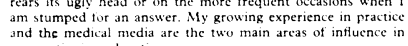
my continung cducation.

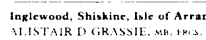

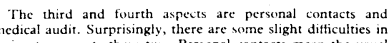

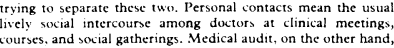

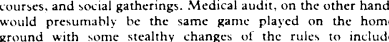

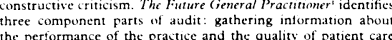

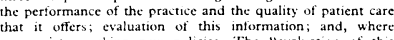

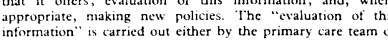

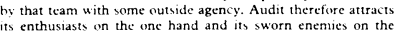

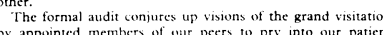

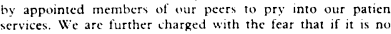

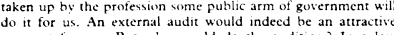

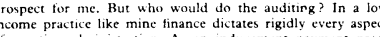

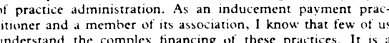

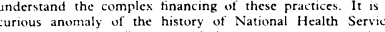

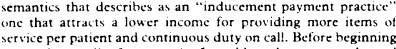

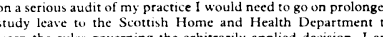

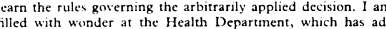

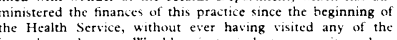
incumbent docturss. would private endustryy permit such

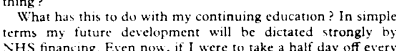

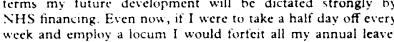

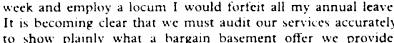

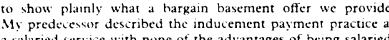
Financing the NHS

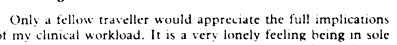

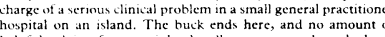

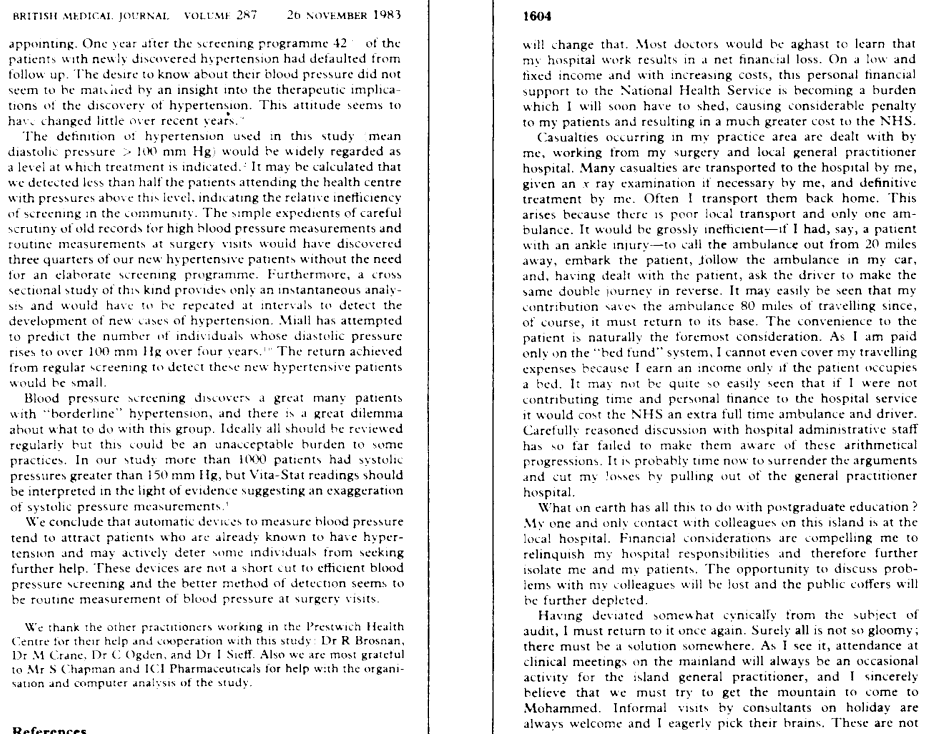

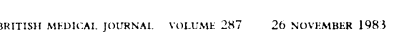

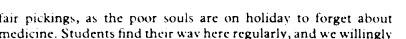

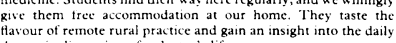

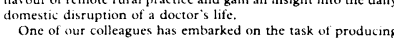

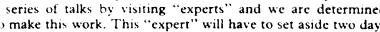

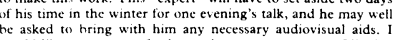

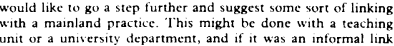
it might promotes a avely academici intercourse bectwen

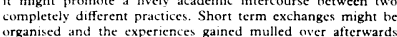

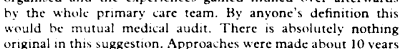

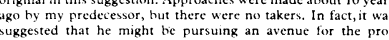

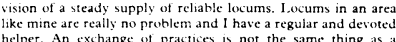
helper. An exthange of practitice is not the same thing as holitaly loceum.
The problems facing un here on Arran as regards continuing

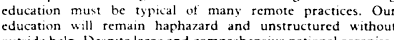

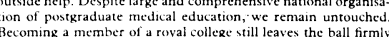

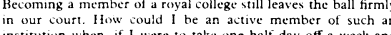

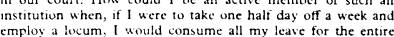

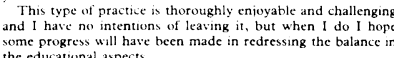
Reference

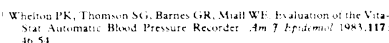

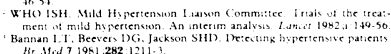

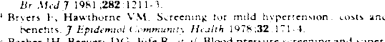

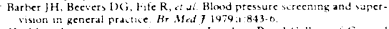

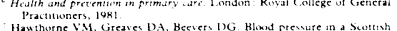

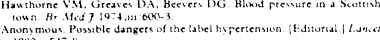

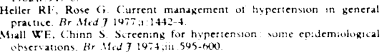

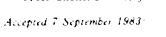

Diary of Urban Marks: 1880-1949

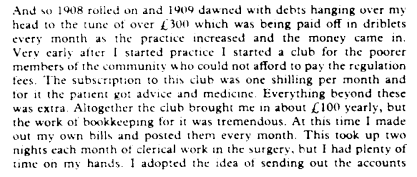

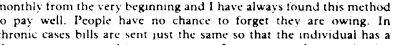

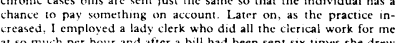

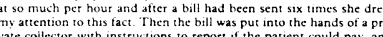

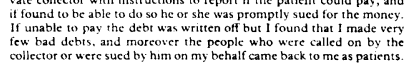

